\title{
The optimal age for performing surgery on patients with MEN 2B syndrome
}

\author{
C. GÓMEZ I GAVARA, J.L. PONCE MARCO, T. BELDA IBAÑEZ, A. BOSCÀ ROBLEDO, C. SEBASTIAN PASTOR, \\ R. NAVARRO MILLA, M. CABALLERO SOTO and M. MESEGUER ANASTASIO
}

Department of Endocrine Surgery, La Fe University Hospital, 46009 Valencia, Spain

Received January 30, 2011; Accepted June 7, 2011

DOI: $10.3892 / \mathrm{ol} .2011 .332$

\begin{abstract}
Multiple endocrine neoplasia (MEN) syndromes are characterized by the association of various endocrine neoplasias. Prophylactic thyroidectomy is the treatment of choice for patients with RET gene mutations. The age at which patients undergo prophylactic thyroidectomy may vary depending on the position of the RET gene codon. In cases of MEN 2B, when the mutation is carried in codons 883,918 or 922 , prophylactic thyroidectomy is performed prior to 6 months of age, due to the increased aggressiveness of these heterozygosities, which are capable of determining the onset of medullary cancer during the first months of life. We present two heterozygous twin patients with MEN 2B syndrome who were born 32 weeks premature, and who underwent prophylactic thyroidectomy at 7 months of age. The patients were carriers of the mutation at codon 918 . We suggested the early surgery at 7 months as, due to their prematurity, the patients were required to gain weight to improve their condition prior to surgery. The two patients had medullary thyroid carcinoma without lymph node involvement. In conclusion, for a truly prophylactic thyroidectomy, such patients should undergo surgery within the first month of life, particularly if these patients are carriers of the mutation in codons 883,918 or 922 .
\end{abstract}

\section{Introduction}

The endocrine abnormalities observed in multiple endocrine neoplasia type 2 (MEN 2) syndrome include medullary thyroid carcinoma, which appears in $100 \%$ of cases and pheochromocytoma, which appears in $50 \%$ of cases. There are two main types of MEN 2: MEN 2A and 2B. There is also a familial form of medullary thyroid cancer. RET proto-oncogene mutations are responsible for the occurrence of these syndromes.

Correspondence to: Dr C. Gómez I Gavara, Department of Endocrine Surgery, La Fe University Hospital, Av. Campanar 21, 46009 Valencia, Spain

E-mail: imgoga@hotmail.com

Key words: MEN 2B syndrome, codons 883, 918, 922, RET mutation
Patients with these mutations should undergo total thyroidectomy surgery at childhood, at specific ages depending on the type of mutation responsible, due to the high risk of developing medullary thyroid carcinoma.

\section{Case report}

C.V.H., a 41-year-old carrier of MEN 2B syndrome, who underwent surgery for pheochromocytoma and medullary thyroid carcinoma, gave birth to heterozygous twins in the 32nd week of pregnancy with a birth weight of $1000 \mathrm{~g}$ (M.V.V.) and $800 \mathrm{~g}$ (O.V.V.).

The patients suffered from MEN 2B, carrying the mutation in codon 918, and underwent total thyroidectomy once a sufficient weight had been achieved (5600 and $4500 \mathrm{~g}$, respectively), at 7 months of age.

In both cases, the patients underwent a total thyroidectomy and central compartment dissection.

The postoperative course was uneventful and the patients were discharged from hospital within $24 \mathrm{~h}$ of surgery. The anatomopathological result of the higher birth weight sibling (M.V.V.) revealed the presence of medullary thyroid carcinoma (MTC) at a diameter of 1x2 $\mathrm{mm}$ in the upper pole of both lobes without lymph node involvement (0/14 andenopathies) following central compartment neck dissection. In the lower weight birth sibling (O.V.V.) the presence of MTC at a diameter of $1 \times 1 \mathrm{~mm}$ was identified in the upper pole of the right lobe and C-cell hyperplasia in the upper pole, also without lymph node involvement (0/10) (Fig. 1).

\section{Discussion}

RET gene mutations are responsible for the onset of MEN 2 syndrome. These mutations are transmitted as an autosomal dominant feature.

The MEN 2B subtype is responsible for approximately $5 \%$ of cases of MEN 2. MEN 2B is characterized by an early development, during the first year of life, of an aggressive form of MTC (1).

Patients with MEN 2B who do not undergo thyroidectomy during the first year of life have a high risk of developing metastatic MTC at an early age. If prophylactic thyroidectomy is not performed early enough, the average life expectancy is 21 years of age. 
A

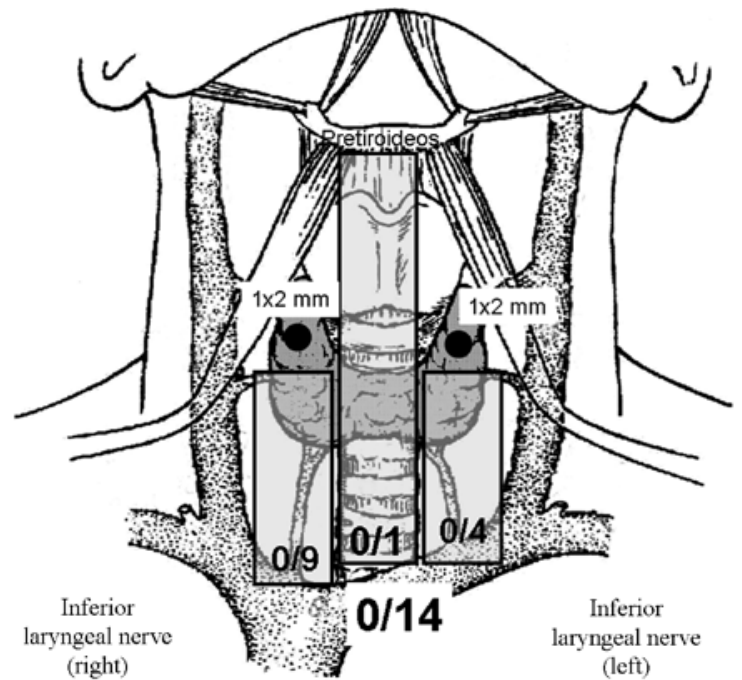

B

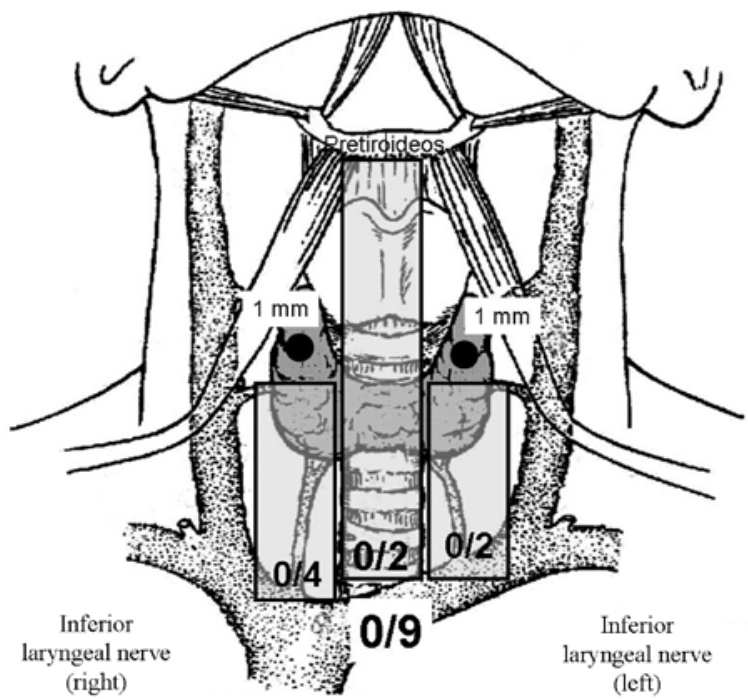

Figure 1. Anatomopathological result of central compartment thyroidectomy and lymphadenectomy in (A) higher birth weight patient (M.V.V.) and (B) lower birth weight patient (O.V.V.)

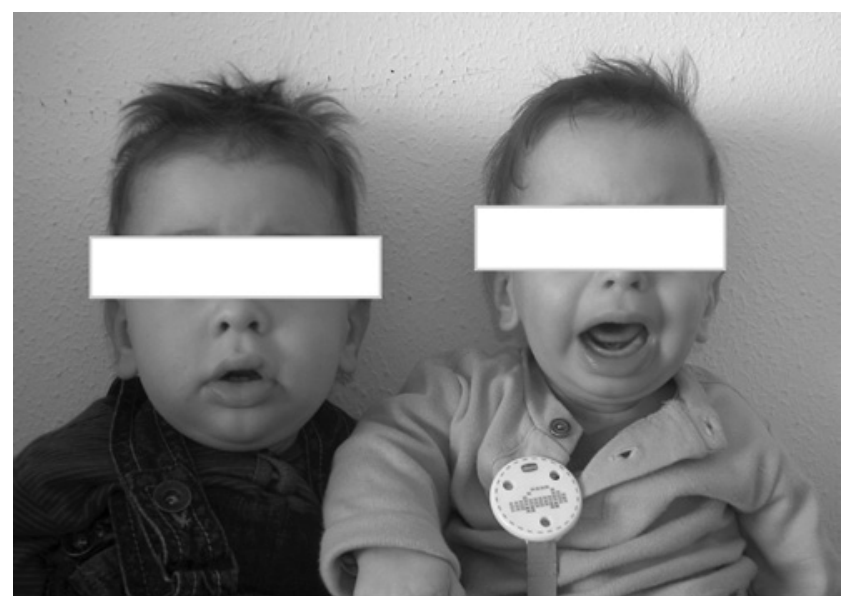

Figure 2. M.V.V. (left) and O.V.V. (right) at 3 months after surgery.
The incidence of pheochromocytoma in patients with MEN 2B is 50\%. Parathyroid adenoma or hyperplasia was not observed in this subtype (2).

In contrast, in $100 \%$ of these patients, it is possible to identify the presence of mucosal neuromas on the anterior dorsal surface of the tongue, palate, or pharynx and characteristic facies from childhood. All cases exhibit a marfanoid habit, often with scoliosis or lordosis, and hypermobility.

Prophylactic thyroidectomy is the treatment of choice for patients with RET gene mutations. According to the consensus of the Seventh International Workshop, the age for prophylactic thyroidectomy may vary depending on the position of the RET gene codon (3). In MEN 2B patients carrying the mutation in codons 883,918 or 922 , prophylactic thyroidectomy is performed prior to 6 months of age, due to the increased aggressiveness of these heterozygosities (4), as they are capable of determining the onset of medullary cancer during the first months of life (5).

In the cases presented here, the patients are carriers of the mutation at codon 918 . Therefore, early surgery was suggested. In both cases surgery occurred at 7 months as, due to their prematurity, the patients needed to gain weight to improve their condition prior to surgery. In any case, due to their premature birth, the situation was as if the patients had undergone surgery at 5 months of age. In both cases, despite the early intervention, it was not possible to perform a prophylactic thyroidectomy, as sites of MTC had already developed. Since surgery was not performed during their first month of life, as is usually the case, a central compartment dissection associated with thyroidectomy was performed. The pathological examination of nodes revealed that the surgery was performed early enough, since no central compartment lymph node was affected.

Therefore, to make a truly prophylactic thyroidectomy, patients should undergo surgery within the first month of life, particularly if they are carriers of the mutation in codons 883,918 or 922 . However, if the surgery is performed prior to the age of 6 months, it is sufficiently early that it may not be necessary to systematically perform central compartment lymphadenectomy.

\section{References}

1. O'Riordain DS, O'Brien T, Weaver AL, Gharib H, Hay ID, Grant CS and van Heerden JA: Medullary thyroid carcinoma in multiple endocrine neoplasia types $2 \mathrm{~A}$ and $2 \mathrm{~B}$. Surgery 116: 1017-1023, 1994.

2. Vasen HF, van der Feltz M, Raue F, Kruseman AN, Koppeschaar HP, Pieters G, Seif FJ, Blum WF and Lips CJ: The natural course of multiple endocrine neoplasia type IIb. A study of 18 cases. Arch Intern Med 152: 1250-1252, 1992.

3. Brandi ML, Gagel RF, Angeli A, Bilezikian JP, Beck-Peccoz P, Bordi C, Conte-Devolx B, Falchetti A, Gheri RG, Libroia A, Lips CJ, Lombardi G, Mannelli M, Pacini F, Ponder BA, Raue F, Skogseid B, Tamburrano G, Thakker RV, Thompson NW, Tomassetti P, Tonelli F, Wells SA and Marx SJ: Guidelines for diagnosis and therapy of MEN type 1 and type 2. J Clin Endocrinol Metab 86: 5658-5671, 2001.

4. Wiesner G and Snow-Bailey K: GeneReviews: Multiple Endocrine Neoplasia Type 2. Update Mar 7, 2005

5. American Thyroid Association Guidelines Task Force, Kloos RT, Eng C, et al: Medullary thyroid cancer: management guidelines of the American Thyroid Association. Thyroid 19: 565, 2009. 